\title{
Single-molecule spectroscopy, imaging, and photocontrol: foundations for super-resolution microscopy (Presentation Video)
}

\section{W. Moerner}

W. E. Moerner, "Single-molecule spectroscopy, imaging, and photocontrol: foundations for super-resolution microscopy (Presentation Video)," Proc. SPIE 9331, Single Molecule Spectroscopy and Superresolution Imaging VIII, 93311E (22 April 2015); doi: 10.1117/12.2197198

SPIE. Event: SPIE BiOS, 2015, San Francisco, California, United States 


\title{
Single-molecule spectroscopy, imaging, and photocontrol: foundations for super-resolution microscopy (Presentation Video)
}

\author{
W. E. Moerner, Stanford University (USA)
}

\begin{abstract}
W. E. Moerner, the Harry S. Mosher Professor of Chemistry and professor, by courtesy, of Applied Physics at Stanford University, conducts research in physical chemistry of single molecules, biophysics, nanoparticle trapping, and nanophotonics. He earned three bachelor's degrees from Washington University in 1975 and master's and doctoral degrees from Cornell University in 1978 and 1982. From 1981 to 1995 , he was a research staff member at IBM, receiving two IBM Outstanding Technical Achievement Awards. He was Professor and Distinguished Chair in Physical Chemistry at the University of California, San Diego, from 1995 to 1998, the year he joined the Stanford faculty. Moerner received the 2014 Nobel Prize in Chemistry, along with Eric Betzig and Stefan Hell, for their development of super-resolved fluorescence microscopy.
\end{abstract}

View presentation video on SPIE's Digital Library: http://dx.doi.org/10.1117/12.2197198.4078402980001

Single Molecule Spectroscopy and Superresolution Imaging VIII, edited by Jörg Enderlein, Ingo Gregor,

Zygmunt Karol Gryczynski, Rainer Erdmann, Felix Koberling, Proc. of SPIE Vol. 9331, 93311E

(C) 2015 SPIE · CCC code: 1605-7422/15/\$18 · doi: 10.1117/12.2197198

Proc. of SPIE Vol. $933193311 \mathrm{E}-1$ 